\title{
Correction to: Design and implementation of an autonomous EGR cooling system using deep neural network prediction to reduce NOx emission and fuel consumption of diesel engine
}

\author{
Halil Ibrahim Akolaş ${ }^{1} \cdot$ Alirıza Kaleli $^{2}$ (1) $\cdot$ Kadir Bakirci $^{3}$
}

Published online: 5 October 2020

(C) Springer-Verlag London Ltd., part of Springer Nature 2020

\section{Correction to: \\ Neural Computing and Applications \\ https://doi.org/10.1007/s00521-020-05104-1}

Unfortunately, one of the co-author's family name (Kadir Bakirci) and his e-mail address have been published incorrectly in the online version of the article.
The correct family name should be Bakirci and the e-mail address should be as follows: abakirci@ atauni.edu.tr

Publisher's Note Springer Nature remains neutral with regard to jurisdictional claims in published maps and institutional affiliations.

The original article can be found online at https:// doi.org/10.1007/s00521-020-05104-1.

Alirıza Kaleli

aliriza.kaleli@samsun.edu.tr

Halil İbrahim Akolaş

hakolas@beu.edu.tr

Kadir Bakirci

abakirci@atauni.edu.tr

1 Vocational School of Ahlat, Bitlis Eren University, 13400 Bitlis, Turkey

2 Department of Electrical-Electronics Engineering, Faculty of Engineering, Samsun University, 55080 Samsun, Turkey

3 Department of Mechanical Engineering, Faculty of Engineering, Atatürk University, 25240 Erzurum, Turkey 